\title{
Zoledronic acid exhibits radio-sensitizing activity in human pancreatic cancer cells via inactivation of STAT3/NF-kB signaling
}

This article was published in the following Dove Press journal: OncoTargets and Therapy

\author{
Yanjie You ${ }^{1, *}$ \\ Qiang Wang ${ }^{2, *}$ \\ Haijun $\mathrm{Li}^{3, *}$ \\ Yuhong $\mathrm{Ma}^{\mathrm{l}}$ \\ Yanhong Deng' \\ Zhengcai $\mathrm{Ye}^{4}$ \\ Feihu Bai'
}

'Department of Gastroenterology, Ningxia Hui Autonomous Region

People's Hospital, Yinchuan, Ningxia Hui Autonomous Region 75002I, People's

Republic of China; ${ }^{2}$ Department of Science and Education, Ningxia Hui

Autonomous Region People's Hospital, Yinchuan 75002I, People's Republic of

China; ${ }^{3}$ Department of Radiation

Oncology, The Second People's Hospital of Neijiang, Neijiang, Sichuan 641003,

People's Republic of China; ${ }^{4}$ Endoscopy

Center, Ningxia Hui Autonomous Region

People's Hospital, Yinchuan 75002I,

People's Republic of China

*These authors contributed equally to this work

Correspondence: Yanjie You; Feihu Bai Department of Gastroenterology, Ningxia Hui Autonomous Region People's Hospital, 30I Zhengyuan North Road, Yinchuan, Ningxia Hui Autonomous Region 75002I, People's Republic of China

$\mathrm{Tel} / \mathrm{fax}+86$ 95I 5920123

Email youyanjie@।63.com;

baifeihu@sohu.com
Background: Although pancreatic cancer is typically radio-sensitive, local treatment failure and metastasis are commonly caused by the development of resistance to radiotherapy. In the current study, the radio-sensitizing actions of zoledronic acid (ZOL) on pancreatic cancer cells were investigated.

Materials and methods: Three human pancreatic cancer cell lines were exposed to ZOL, ionizing radiation (IR), or a combination of both, and the effects of the respective drug regimens on cell proliferation and invasion were examined.

Results: Combined treatment with low doses of ZOL plus IR efficiently increased cell death and attenuated cell invasion compared with the individual use of ZOL or IR. These effects of ZOL were associated with inactivation of signal transducer and activator of transcription 3 (STAT3) and nuclear factor- $\kappa \mathrm{B}(\mathrm{NF}-\kappa \mathrm{B})$.

Conclusion: Collectively, these data suggest that ZOL in combination with IR is a promising therapeutic strategy for enhancing radio-sensitivity in pancreatic cancer cells via downregulation of the STAT3/NF- $\kappa$ B signaling pathway.

Keywords: pancreatic cancer, radio-resistance, zoledronic acid, radio-sensitizing effects

\section{Introduction}

Due to the high risk of local disease progression and metastasis, pancreatic cancer ranks as the fourth leading cause of cancer-associated mortality worldwide, with an overall 5-year survival rate of $6.7 \%{ }^{1-3}$ Despite increasing advances in clinical imaging technologies, the diagnosis of pancreatic cancer typically occurs during the advanced stage of this malignancy for the majority of patients. Currently, conventional adjuvant therapies, including chemotherapy and radiotherapy, have limited beneficial impact on advanced pancreatic cancer. ${ }^{4}$ Therefore, it is urgent to identify reliable drugs that may sensitize pancreatic cancer cells to increase the response to standard chemotherapy and radiotherapy.

Bisphosphonates are the most effective inhibitors of osteoclast-mediated bone resorption and have been widely used to treat osteoclast-mediated metabolic bone diseases. ${ }^{5-8}$ Zoledronic acid (ZOL), a third-generation bisphosphonate, has been demonstrated to act synergistically with other chemical substances, predominantly due to an increase in the proportions of cells in S-phase of the cell cycle. ${ }^{9-14}$ This suggests that $\mathrm{ZOL}$ could serve as a potent radio-sensitizer, as decelerated progression through S-phase or a blockade between $\mathrm{S}$ and $\mathrm{G}_{2} \mathrm{M}$ phases results in increased sensitivity of cancer cells to radiotherapy. ${ }^{15}$ 
Our previous study reported the synergistic radiosensitizing effects of ZOL on human esophageal squamous cell carcinoma cells. ${ }^{16}$ Treatment with ZOL also reversed the cisplatin resistance in nasopharyngeal carcinoma cells. ${ }^{17}$ On the basis of our previous study and others, combined application of ZOL and ionizing radiation (IR) may be useful for cancer therapy without excessive side effects and complications. ${ }^{9-14,17}$ However, the radiosensitizing ability of ZOL on pancreatic cancer remains to be elucidated. Consequently, in the present, whether treatment with ZOL could augment the cytotoxic effects of IR was examined. The associated molecular mechanisms were then analyzed to understand the radiosensitizing effect of ZOL on pancreatic cancer cells.

\section{Materials and methods}

\section{Cell culture and reagents}

Three human pancreatic cancer cell lines, MIA-PaCa2 PANC-1 and BxPC3, were cultured as described previously. ${ }^{18,19}$ An immortalized pancreatic ductal epithelial cell line, $\mathrm{H} 6 \mathrm{C} 7$, was cultured in Defined Keratinocyte-serum free medium (Gibco; Thermo Fisher Scientific, Inc., Waltham, MA, USA). Zoledronic acid (ZOL) was provided by Novartis International AG (Basel, Switzerland). Stock solution of ZOL was prepared at $10 \mathrm{mM}$ in $0.9 \%$ saline, stored at $-20^{\circ} \mathrm{C}$ and added to Dulbecco's modified Eagle's medium (DMEM; Gibco; Thermo Fisher Scientific, Inc.) immediately prior to application. All cell lines were kindly provided by Dr Yonggang Ran (Medical NCO Academy of PLA, Shijiazhuang, China) and the employment of these cell lines was approved by the Institutional Review Board and the Ethics Committee of Ningxia Hui Autonomous Region People's Hospital.

\section{Cell viability assay}

An MTT colorimetric assay was performed to measure the growth rate of tumor cells following exposure of ZOL, as described previously. ${ }^{18,19}$ Briefly, cells were plated in triplicate at a density of $4 \times 10^{3}$ cells per well on 96-well plates (Corning Costar, Cambridge, MA, USA). After $24 \mathrm{hrs}$ of culture at $37^{\circ} \mathrm{C}$, cells were incubated with $\mathrm{ZOL}$ at various concentrations (2-64 $\mu \mathrm{M})$ at $37^{\circ} \mathrm{C}$ for $72 \mathrm{hrs}$, followed by MTT assays. The purple formazan in each well was dissolved in dimethyl sulfoxide (Sigma-Aldrich; Merck KGaA, Darmstadt, Germany) and measured at $490 \mathrm{~nm}$.

\section{Colony formation assay}

This procedure was performed as previously described. ${ }^{14,16}$ Cells were plated at different densities in 6-well plates and allowed to attach for $12 \mathrm{hrs}$. Then, the cells were treated with $2 \mu \mathrm{M}$ ZOL for $6 \mathrm{hrs}$ and transiently exposed to graded doses of irradiation (from 2 to $6 \mathrm{~Gy}, 1$ Gy per min) using the Gammacell ${ }^{\circledR} 3000$ Elan system (Nordion, Inc., Ottawa, ON, Canada). The media were changed $24 \mathrm{hrs}$ after radiation exposure and cells were incubated for 2 weeks. Subsequently, cellular colonies were stained with $0.5 \%$ crystal violet (Sigma-Aldrich; Merck KGaA, Darmstadt, Germany). The number of colonies was counted, and images were captured using a light microscope (magnification, x100; Carl Zeiss AG, Oberkochen, Germany). Only colonies with $>50$ cells were counted. Each surviving fraction (SF) was calculated by dividing the number of cellular clones by the number of cells plated per plate, then normalizing the SF for each radiation dose to the $\mathrm{SF}$ of untreated cells.

\section{Cell cycle analysis}

Flow cytometry was performed to determine whether the activity of ZOL was associated with changes in cell cycle distribution. In brief, cells were treated with $2 \mu \mathrm{M}$ ZOL 12 hrs after plating and exposed to a single 4 Gy IR dose $6 \mathrm{~h}$ later. Media were changed the following day, and cells were harvested and fixed in $70 \%$ ethanol at $-20^{\circ} \mathrm{C}$. Cells were suspended in $500 \mu \mathrm{L}$ solution containing $10 \mu \mathrm{g} / \mathrm{mL}$ propidium iodide, $100 \mu \mathrm{g} / \mathrm{mL}$ RNase, and $20 \mathrm{mM}$ ethylene-diaminetetraacetic acid. After $1 \mathrm{hr}$ of incubation at $37^{\circ} \mathrm{C}$, flow cytometry analyses were performed. DNA content and percentages of cells in each phase of the cells cycle were analyzed using a FACSCalibur cytometer (BD Biosciences; Becton, Dickinson and Company, Franklin, Lakes, NJ, USA).

\section{Cell invasion assay}

The cell invasion assay was performed as described previously. ${ }^{14,18,19}$ Briefly, cells were pretreated with $2 \mu \mathrm{M}$ ZOL and then plated in 24-well Matrigel-coated Transwell inserts (EMD Millipore, Billerica, MA, USA) at $5 \times 10^{4}$ cells per in $500 \mu \mathrm{L}$ serum-free DMEM. The lower chamber of the Transwell insert was filled with $750 \mu \mathrm{L}$ DMEM with $10 \%$ fetal bovine serum (Gibco; Thermo Fisher Scientific, Inc.). Irradiation (4 Gy) was immediately applied to cells. Following incubation at $37^{\circ} \mathrm{C}$ for $24 \mathrm{hrs}$, non-invasive cells in the upper chamber were removed. Invasive cells on the lower surface of the inserts were fixed with $4 \%$ 
paraformaldehyde at room temperature for 30 mins. Crystal violet (4\%) was used to stain the migrated cells for 15 mins at room temperature, which were then counted using an inverted microscope at x100 magnification. Invasion activity was assessed as the mean number of invaded cells in three randomly selected microscopic fields.

\section{Western blot analysis}

Western blot analysis was performed as described previously. ${ }^{15,20}$ The membrane containing transferred protein was incubated with the following primary antibodies overnight at $4{ }^{\circ} \mathrm{C}$ : Rabbit polyclonal antibodies against signal transducer and activator of transcription 3 (STAT3; cat. no. sc-482; dilution, 1:400; Santa Cruz Biotechnology, Inc., Dallas, TX, USA), phospho (p)-STAT3 (cat. no. sc-8059; dilution, 1:500; Santa Cruz Biotechnology, Inc.), p65 (cat. no. sc-7151; dilution, 1:400; Santa Cruz Biotechnology, Inc.) and cyclooxygenase-2 (COX-2; cat. no. sc-23,983; dilution, 1:400; Santa Cruz Biotechnology, Inc.). Following washing with $0.1 \%$ Tween-20 in PBS, the membranes were then incubated with the following horseradish peroxidase-conjugated secondary antibodies for $1 \mathrm{~h}$ at $37^{\circ} \mathrm{C}$ : Goat anti-rabbit immunoglobulin G (IgG; cat. no. sc-2004; dilution, 1:2,000; Santa Cruz Biotechnology, Inc.). Proteins were detected using an enhanced chemiluminescence kit (GE Healthcare Life Sciences, Chalfont, UK). Anti-GAPDH monoclonal antibody (cat. no. ab9485; dilution, 1:2,500; Abcam, Cambridge, MA, USA) was used to ensure equal loading of protein.

\section{Statistical analysis}

Statistical analysis was performed using the SPSS statistical software package (version 17.0; SPSS Inc., Chicago, IL, USA). Data from at least three independent experiments are presented as the mean \pm standard deviation. Data were analyzed using a paired $t$-test with Bonferroni adjustment or one-way analysis of variance, followed by the StudentNewman-Keuls post hoc test for multiple comparisons. $P<0.05$ was considered to indicate a statistically significant difference.

\section{Results}

\section{ZOL inhibits the proliferation of pancreatic cancer cells}

Results from MTT assays revealed that treatment with ZOL dose-dependently decreased the cell viability of all three pancreatic cancer cell lines (Figure 1). Notably, the anti-growth effects of ZOL were slightly different for each cell line; MIA-PaCa2 and $\mathrm{BxPC} 3$ cells exhibited a more sensitive cellular response to ZOL than PANC-1 cells. Notably, the viability of $\mathrm{H} 6 \mathrm{C} 7$ immortalized pancreatic epithelial cells was unaffected by ZOL, even when exposed to high doses. This suggests a wide range of drug activity depending on the intrinsic differences between the cell lines.

\section{ZOL augments IR-induced clonogenic cell death}

Analyses of clonogenicity were subsequently conducted to examine the percentage of surviving cellular clones following exposure to ZOL and IR. Based on the above results, a relatively low dose of ZOL was selected to avoid excessive toxicity in all subsequent studies $(2 \mu \mathrm{M}$ ZOL pre-treatment prior to irradiation). Co-treatment of three pancreatic cancer cell lines with ZOL and IR markedly increased clonogenic cell death compared with IR treatment alone (Figure 2). However, this radiosensitizing effect was not observed in $\mathrm{H} 6 \mathrm{C} 7$ pancreatic epithelial cells.

\section{ZOL induces S-phase cell cycle arrest}

The association between combined treatment with ZOL plus IR and changes in cell cycle distribution was investigated. Flow cytometry revealed that combined treatment of MIA$\mathrm{PaCa} 2$ cells with a lower concentration of ZOL $(2 \mu \mathrm{M})$ and a single dose of IR (4 Gy) led to an increase in the proportion of cells in S-phase (Figure 3). Combination of ZOL and IR resulted in more significant effect than use of either ZOL or IR alone, indicating synergistic function. In addition, cotreatment with ZOL and IR induced a marginal upregulation in the proportion of subG1-phase cells.

\section{Co-treatment with ZOL and IR exhibits enhanced anti-invasive effects on pancreatic cancer cells}

It has been previously reported that ZOL inhibits the migration and invasion of cancer cells. ${ }^{14}$ Therefore, it was further analyzed whether co-treatment with ZOL and IR could augment the anti-invasion effect induced by their use individually. Invasion assays were performed using MIA-PaCa 2 cells following exposure to ZOL and/or IR. ZOL alone significantly reduced the number of invaded cells compared with the control (Figure 4). This anti-invasive effect was enhanced significantly when ZOL was combined with IR, 

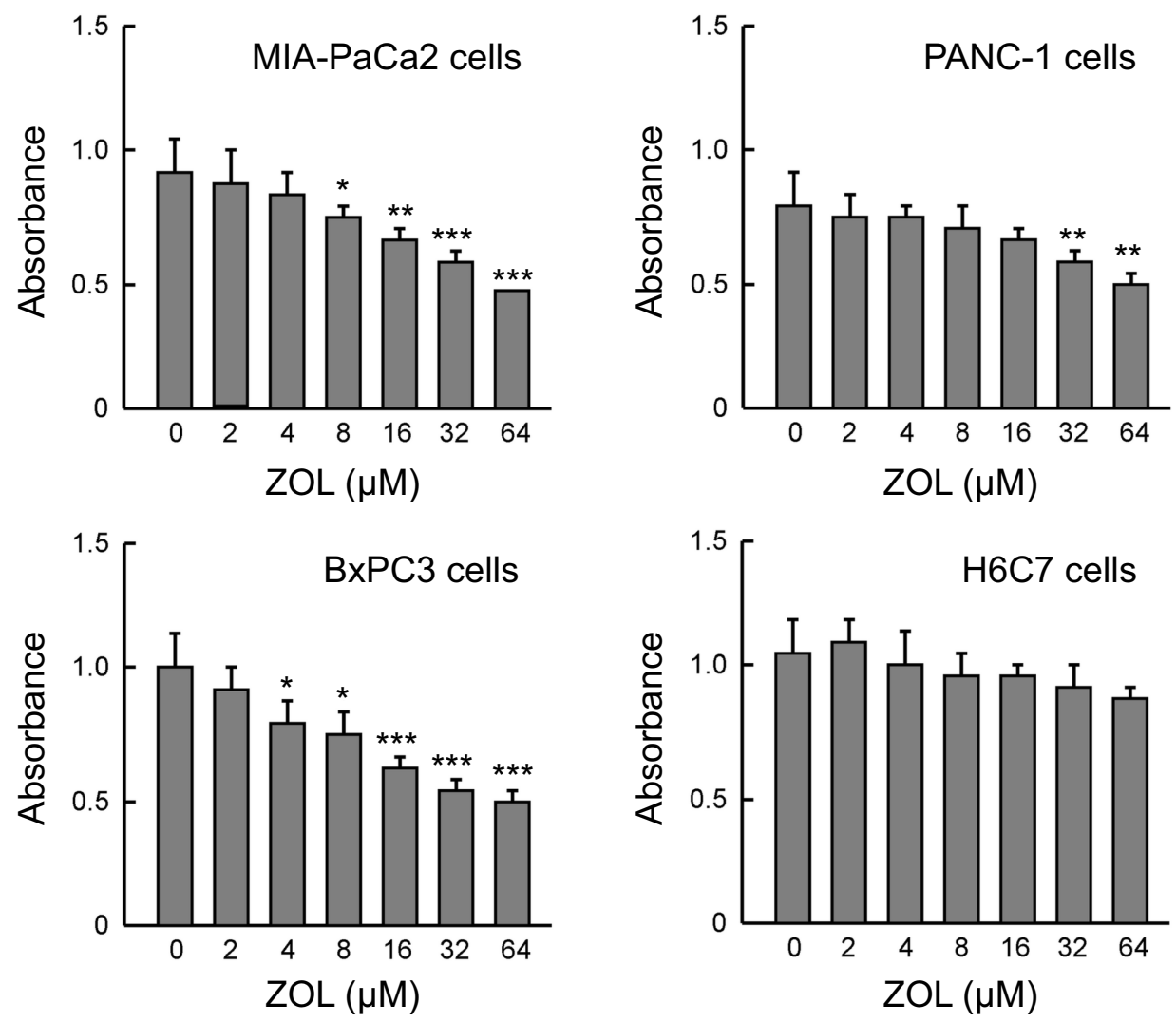

Figure I ZOL inhibits the proliferation of pancreatic cancer cells. Cells were either treated with vehicle control (PBS) or ZOL (2-64 $\mu \mathrm{M})$ for 48 hrs. Cell viability was assessed by MTT assay. The results were representative of three independent experiments. $* P<0.05, * * P<0.01, * * * P<0.001$ vs control group.

Abbreviation: ZOL, zoledronic acid.

although this inhibitory effect was not markedly different to the effect of IR treatment alone.

\section{ZOL and IR inactivate STAT3/NF- $\kappa B$ signaling}

To further determine the molecular mechanism by which ZOL induces anti-proliferative and anti-metastatic effects in pancreatic cancer cells, STAT3 and NF- $\kappa B$, two critical cancer-associated regulators, were analyzed. Western blot analysis revealed that the levels of $p$-STAT3 and $\mathrm{p} 65$, a crucial NF- $\mathrm{BB}$ subunit, were decreased by ZOL treatment (Figure 5). This effect was significantly augmented by combined treatment with ZOL and IR. Notably, the expression of COX-2, a downstream target gene of the NF- $\kappa \mathrm{B}$ pathway, was also increased. However, treatment with IR alone failed to change the expression patterns. These data suggest that inactivation of STAT3/NF- $\mathrm{KB}$ signaling may have an important role in the radio-sensitivity of human pancreatic cancer cells induced by ZOL.

\section{Discussion}

Multiple chemotherapeutic agents have been reported to act as radio-sensitizers when used in combination with radiotherapy. For instance, 5-fluorouracil and cisplatin are commonly used as radio-sensitizers in cancer therapy. ${ }^{21,22}$ Furthermore, various novel plant extracts and targeted biological agents exhibit radio-sensitizing effects. $^{23,24}$ As a third generation of bisphosphonate, ZOL has been demonstrated to cause cell cycle arrest at the S-phase or G2/M transition, subsequently resulting in cell apoptosis. ${ }^{23,24}$ This function suggests that ZOL could be used as a potential radio-sensitizer, as cells in $\mathrm{G} 2 / \mathrm{M}$ are more sensitive to radiation than cells in other phases of the cell cycle. ${ }^{13-17}$ In the present study, a significant synergistic anti-tumor effect was produced by combined treatment of in pancreatic cancer cells with ZOL and IR, which was at least partially due to inactivation of STAT3/NF- $\kappa \mathrm{B}$ signaling. The data provide a novel insight into future application of ZOL combined with IR therapy. 

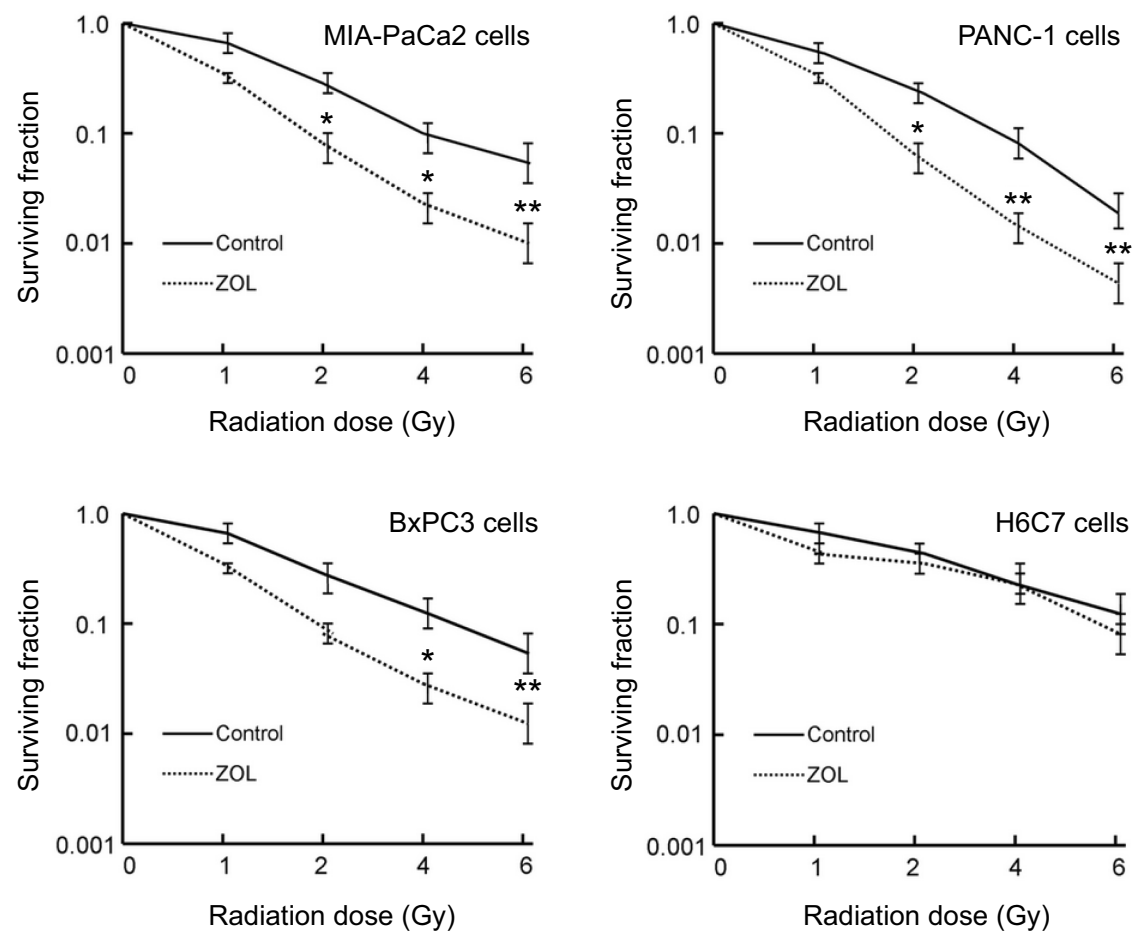

MIA-PaCa2 cells

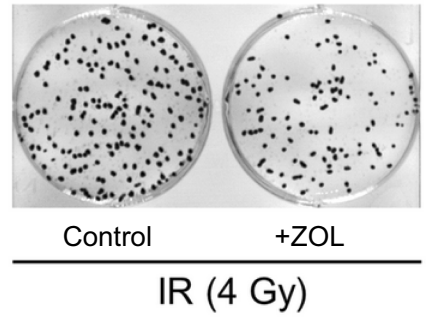

PANC-1 cells

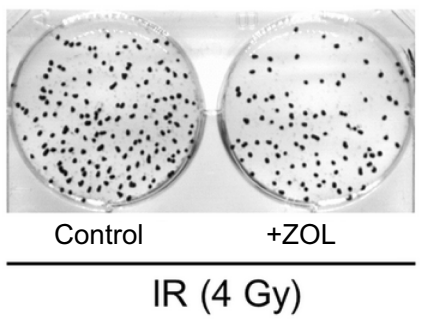

\section{BxPC3 cells}

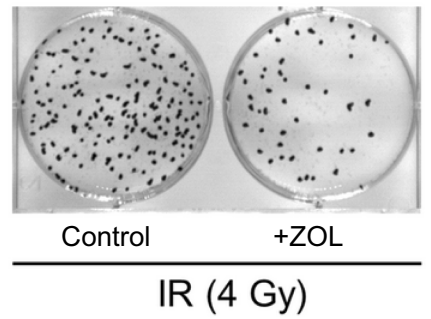

H6C7 cells

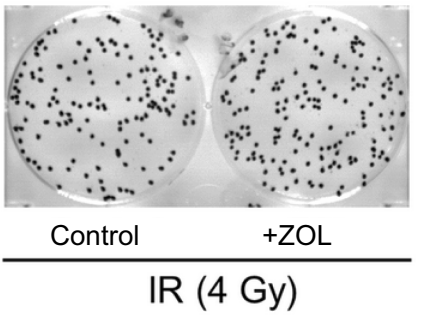

Figure 2 ZOL affects clonogenic survival synergistically with IR in pancreatic cancer cells. Cells were pretreated with vehicle control or $2 \mu M$ ZOL for 6 hrs before exposure to IR at the indicated doses. Media were changed the following day and cells were maintained in normoxic conditions for I2-I4 days prior to counting. Cell colonies were stained, and the SF was determined by colony counting. Clonogenic curves are presented in the upper panel and the represented images are shown in the lower panel, respectively. Data are presented as the mean \pm standard deviation of three independent experiments. $* P<0.05 ; * * P<0.01$.

Abbreviations: ZOL, zoledronic acid; IR, ionizing radiation; SF, surviving fraction.

ZOL treatment alone exhibited significant antiproliferative effects in a dose range of 8-64 $\mathrm{mM}$. This result is supported by various other reports in vitro. . $^{411,14,16,17,20}$ However, it is well established that ZOL has a rapid clearance rate from the blood, which limits its clinical application. ${ }^{25}$ Thus, an important future direction of ZOL application is use in combination with other chemicals and biological agents to produce synergistic efficiency, with the potential to allow lower and less toxic doses of each drug to be administered. ${ }^{16,17}$ The results suggest a novel strategy for treating pancreatic cancer by combination of ZOL and IR. Notably, pancreatic cancer cells exhibited enhanced 


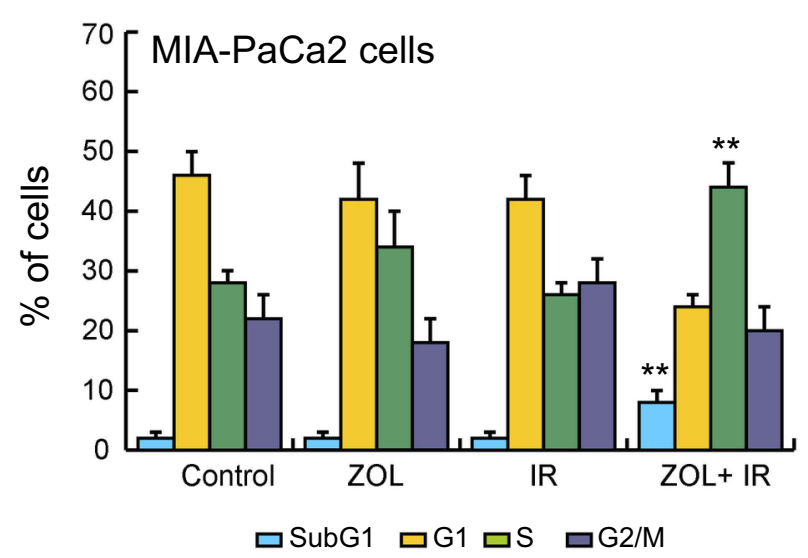

Figure $3 \mathrm{~S}$-phase cell cycle arrest induced by ZOL plus IR. MIA-PaCa2 cells were treated with $2 \mu \mathrm{M}$ ZOL and irradiated 6 hrs later with 4 Gy. Media were changed the following day. Cell cycle distribution was assessed by flow cytometry at $24 \mathrm{hrs}$ after irradiation (30 hrs after exposure to $\mathrm{ZOL})$. ${ }^{* * P}<0.01$.

Abbreviations: ZOL, zoledronic acid; IR, ionizing radiation.

radio-sensitivity when IR used as a combined treatment with low doses of ZOL; however, the sensitivity of $\mathrm{H6C7}$ immortalized normal pancreatic ductal epithelial cell line was not affected by ZOL, indicating that the radiosensitizing effect of ZOL may be tumor-specific.

Generally, tumor cells are most sensitive to radiotherapy during late $\mathrm{S}$ and $\mathrm{G} 2 / \mathrm{M}$ phases. ${ }^{26}$ It is reported that the proportion of multiple myeloma cells in $\mathrm{S}$ phase was increased following exposure to $\mathrm{ZOL}$, potentially due to slowing of progression through $\mathrm{S}$ phase or arrest between $\mathrm{S}$ and $\mathrm{G} 2 / \mathrm{M}$ in the cell cycle. ${ }^{10}$ Recently, it was also demonstrated that the $\mathrm{S}$ phase cell cycle arrest induced by ZOL may be mediated by elevated levels of cyclin A and cyclin B in

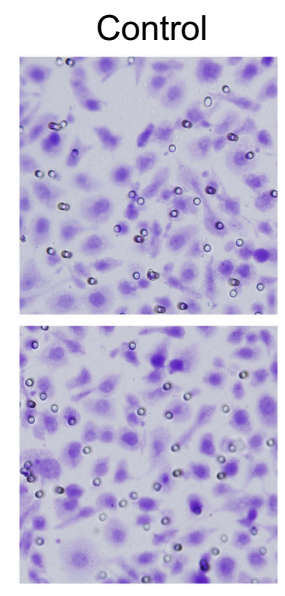

IR

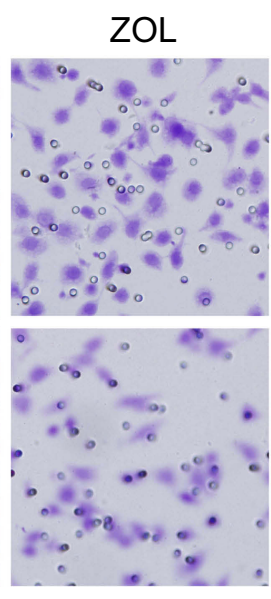

$Z O L+I R$
$\mathrm{S}$ and $\mathrm{M}$ phases, and by decreased $\mathrm{p} 21^{\mathrm{Cip} 1}$ expression. ${ }^{14} \mathrm{In}$ addition, we found that $\mathrm{ZOL}$ reverses cisplatin resistance in nasopharyngeal carcinoma cells by activating the mitochondrial apoptotic pathway. ${ }^{17}$ Exposure of cisplatin-resistant cells to ZOL resulted in upregulated expression of BAX and caspase-9, and downregulated expression of BCL-2. A previous study has revealed that ZOL induces antiproliferative and apoptotic effects in human pancreatic cancer cells in vitro. ${ }^{27}$ The proapoptotic effect was correlated to cleavage/activation of caspase-9 and poly(ADP)-ribose polymerase, but not of caspase-3. In the current study, the proportion of cells cell in S phase was increased by ZOL treatment; however, no significant alteration was observed compared with the control treatment. By contrast, combined treatment with ZOL and IR resulted in a significantly increased proportion of S phase cells, suggesting ZOL and radiation exert synergistic effects. This finding is consistent with our previous reports. ${ }^{14,16}$

Our previous studies have also demonstrated that ZOL inhibits invasion and migration of nasopharyngeal carcinoma cells via attenuation of vascular endothelial growth factor and matrix metalloproteinases (MMPs) ${ }^{20}$ This observation is consistent with the finding in another report on pancreatic cancer, which suggested that combined treatment with ZOL and gemcitabine has significant anti-proliferative, antimetastatic and anti-angiogenic effects on pancreatic cancer cells in vitro and in vivo. ${ }^{4}$ It has also been reported that $\mathrm{ZOL}$ suppresses the invasiveness of pancreatic cancer cells by downregulating the expression of MMP-2 and MMP-9. ${ }^{4}$ Additionally, the STAT3/NF- $\mathrm{kB}$ signaling has been identified

Figure 4 Combined treatment with ZOL plus IR decreases invasiveness of pancreatic cancer cells. MIA-PaCa2 cells were treated with $2 \mu M$ ZOL 24 hrs after platting and then irradiated with $4 \mathrm{~Gy}$ after $6 \mathrm{hrs}$. Cells invasion assays were then performed. The experiments were repeated three times in triplicate. Data are presented as the mean \pm standard deviation. $* * P<0.01$, $* * * P<0.001$.

Abbreviations: ZOL, zoledronic acid; IR, ionizing radiation.

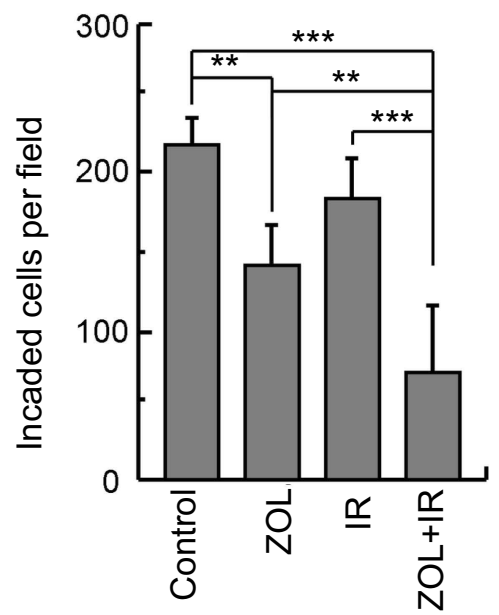




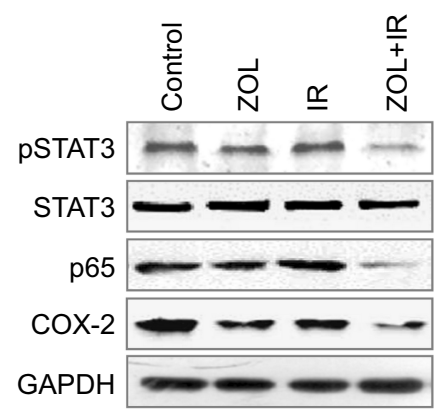

Figure 5 Inactivation of STAT3/NF-KB signaling is involved in enhanced radiosensitivity induced by ZOL plus IR. MIA-PaCa2 cells were treated with $2 \mu \mathrm{M}$ ZOL (6-hr exposure) then cells were irradiated (4 Gy single fraction). Western blot analyses were performed at $24 \mathrm{hrs}$ after irradiation using antibodies against the indicated proteins.

Abbreviations: ZOL, zoledronic acid; IR, ionizing radiation; STAT3, signal transducer and activator of transcription 3; NF- $\mathrm{KB}$, nuclear factor- $\mathrm{KB}$.

as an important pathway that regulates cancer progression, particularly in inflammation-driven tumorigenesis and metastasis. ${ }^{28}$ Inactivation of STAT3/NF- $\mathrm{KB}$ signaling in pancreatic cancer cells may mediate the anti-proliferative and anti-metastatic effects of ZOL and IR combined treatment.

In summary, ZOL combined with IR was demonstrated to reduce the proliferation and invasion of pancreatic cancer cells. These results confirm that cotreatment with $\mathrm{ZOL}$ and IR results in a synergistic effect, which is greater than the effects of their use individually. Additionally, inactivation of STAT3/NF$\kappa \mathrm{B}$ signaling has an important role in the radiosensitivity of human pancreatic cancer cells induced by ZOL. Overall, the findings of the current study offer a promising strategy for the future application of this drug regimen in patients with pancreatic cancer.

\section{Availability of data and materials}

The dataset used and/or analyzed in the current study is available from the corresponding authors on reasonable request.

\section{Acknowledgments}

We thank Mr. Zhen Zhang (Department of Biochemistry and Molecular Biology, University of Kansas Medical Center) for his careful reading of this manuscript and kind suggestions. The present study was supported in part by the National Natural Science Foundation of China (grant nos. 81860426 and 81760440) and the Natural Science Foundation of Ningxia, China (grant no. 2018AAC02016).

\section{Disclosure}

The authors report no conflicts of interest in this work.

\section{References}

1. Bray F, Ferlay J, Soerjomataram I, Siegel RL, Torre LA, Jemal A. Global ancer tatistics 2018: GLOBOCAN estimates of incidence and mortality worldwide for 36 cancers in 185 countries. CA Cancer J Clin. 2018;68(6):394-424. doi:10.3322/caac.21492

2. Hidalgo M, Cascinu S, Kleeff J, et al. Addressing the challenges of pancreatic cancer: future directions for improving outcomes. Pancreatology. 2015;15(1):8-18. doi:10.1016/j.pan.2014.10.001

3. Siegel RL, Miller KD, Jemal A. Cancer statistics, 2018. CA Cancer J Clin. 2018;68(1):7-30. doi:10.3322/caac.21442

4. Zhao M, Tominaga Y, Ohuchida K, et al. Significance of combination therapy of zoledronic acid and gemcitabine on pancreatic cancer. Cancer Sci. 2012;103(1):58-66. doi:10.1111/j.1349-7006.2011. 02113.X

5. Li YY, Chang JW, Chou WC, et al. Zoledronic acid is unable to induce apoptosis, but slows tumor growth and prolongs survival for non-small-cell lung cancers. Lung Cancer. 2008;59(2):180-191. doi:10.1016/j.lungcan.2007.08.026

6. Guenther A, Gordon S, Tiemann M, et al. The bisphosphonate zoledronic acid has antimyeloma activity in vivo by inhibition of protein prenylation. Int J Cancer. 2010;126(1):239-246. doi:10.1002/ ijc. 24758

7. Sewing L, Steinberg F, Schmidt H, Goke R. The bisphosphonate zoledronic acid inhibits the growth of HCT-116 colon carcinoma cells and induces tumor cell apoptosis. Apoptosis. 2008;13 (6):782-789. doi:10.1007/s10495-008-0211-z

8. Russel RGG, Rogers MJ. Bisphosphonates: from the laboratory to the clinic and back again. Bone. 1999;25(1):97-106.

9. Vogt U, Bielawski KP, Bosse U, Schlotter CM. Breast tumour growth inhibition in vitro through the combination of cyclophosphamide/ metotrexate/5-fluorouracil, epirubicin/ cyclophosphamide,epirubicin/ paclitaxel, and epirubicin/docetaxel with the bisphosphonates ibandronate and zoledronic acid. Oncol Rep. 2004;12(5):1109-1114.

10. Matsumoto S, Kimura S, Segawa H, et al. Efficacy of the third-generation bisphosphonate, zoledronic acid alone and combined with anti-cancer agents against small cell lung cancer cell lines. Lung Cancer. 2005;47(1):31-39. doi:10.1016/j.lungcan.2004.06.003

11. Ural AU, Yilmaz MI, Avcu F, et al. The bisphosphonate zoledronic acid induces cytotoxicity in human myeloma cell lines with enhancing effects of dexamethasone and thalidomide. Int $J$ Hematol. 2003;78(5):443-449.

12. Milas L, Hunter NR, Mason KA, Kurdoglu B, Peters LJ. Enhancement of tumor radioresponse of a murine mammary carcinoma by paclitaxel. Cancer Res. 1994;54(13):3506-3510.

13. Algur E, Macklis RM, Hafeli UO. Synergistic cytotoxic effects of zoledronic acid and radiation in human prostate cancer and myeloma cell lines. Int J Radiat Oncol Biol Phys. 2005;61(2):535-542. doi:10.1016/j.ijrobp.2004.09.065

14. Du C, Wang Y, Li H, et al. Zoledronic acid augments the radiosensitivity of cancer cells through perturbing S- and M-phase cyclins and p21CIP1 expression. Oncol Lett. 2017;14(4):4237-4242. doi:10.3892/ol.2017.6710

15. Ural AU, Avcu F. Radiosensitizing effect of zoledronic acid in small cell lung cancer. Lung Cancer. 2005;50(2):271-272. doi:10.1016/j. lungcan.2005.06.003

16. You Y, Liu J, Wang Z, et al. The enhancement of radiosensitivity in human esophageal squamous cell carcinoma cells by zoledronic acid and its potential mechanism. Cytotechnology. 2014;66(1):17-25. doi:10.1007/s10616-012-9532-4 
17. You Y, Li H, Chen J, Qin X, Ran Y. Zoledronic acid reverses cisplatin resistance in nasopharyngeal carcinoma cells by activating the mitochondrial apoptotic pathway. Oncol Lett. 2017;13(3):1840-1846. doi: $10.3892 / \mathrm{ol} .2017 .5611$

18. Bai F, Jiu M, You Y, et al. miR-29a-3p represses proliferation and metastasis of gastric cancer cells via attenuating HAS3 levels. Mol Med Rep. 2018;17:8145-8152. doi:10.3892/mmr.2018.8896

19. You Y, Bai F, Ye Z et al. Downregulated CDK10 expression in gastric cancer: association with tumor progression and poor prognosis. $\mathrm{Mol}$ Med Rep. 2018;17(6):6812-6818. doi:10.3892/mmr.2018.8662

20. Li XY, Lin YC, Huang WL, et al. Zoledronic acid inhibits proliferation and impairs migration and invasion through downregulating VEGF and MMPs expression in human nasopharyngeal carcinoma cells. Med Oncol. 2012;29(2):714-720. doi:10.1007/s12032-0119904-1

21. Minsky BD, Cohen AM, Enker WE, et al. Preoperative 5-FU, low-dose leucovorin, and radiation therapy for locally advanced and unresectable rectal cancer. Int J Radiat Oncol Biol Phys. 1997;37 (2):289-295.

22. Zhuang L, Liu F, Peng P, et al. Effect of Ku80 on the radiosensitization of cisplatin in the cervical carcinoma cell line HeLa. Oncol Lett. 2018;15(1):147-154. doi:10.3892/ol.2017.7304
23. Yuk JM, Shin DM, Song KS, et al. Bacillus calmette-guerin cell wall cytoskeleton enhances colon cancerradiosensitivity through autophagy. Autophagy. 2010;6(1):46-60.

24. Feng Z, Xu S, Liu M, Zeng YX, Kang T. Chk1 inhibitor Gö6976 enhances the sensitivity of nasopharyngeal carcinoma cells to radiotherapy and chemotherapy in vitro and in vivo. Cancer Lett. 2010;297(2):190-197. doi:10.1016/j.canlet.2010.05.011

25. Pandya KJ, Gajra A, Warsi GM, Argonza-Aviles E, Ericson SG, Wozniak AJ. Multicenter, randomized, phase 2 study of zoledronic acid in combination with docetaxel and carboplatin in patients with unresectable stage IIIB or stage IV non-small cell lung cancer. Lung Cancer. 2010;67(3):330-338. doi:10.1016/j.lungcan.2009.04.020

26. Sinclair WK. Cyclic $x$-ray responses in mammalian cells in vitro. Radiat Res. 1968;33(3):620-643.

27. Tassone $\mathrm{P}$, Tagliaferri $\mathrm{P}$, Viscomi $\mathrm{C}$, et al. Zoledronic acid induces antiproliferative and apoptotic effects in humanpancreatic cancer cells in vitro. Br J Cancer. 2003;88(12):1971-1978. doi:10.1038/sj. bjc. 6600986

28. Bollrath J, Greten FR. IKK/NF-kappaB and STAT3 pathways: central signalling hubs in inflammation-mediated tumour promotion and metastasis. EMBO Rep. 2009;10(12):1314-1319. doi:10.1038/ embor.2009.243

\section{Publish your work in this journal}

OncoTargets and Therapy is an international, peer-reviewed, open access journal focusing on the pathological basis of all cancers, potential targets for therapy and treatment protocols employed to improve the management of cancer patients. The journal also focuses on the impact of management programs and new therapeutic agents and protocols on patient perspectives such as quality of life, adherence and satisfaction. The manuscript management system is completely online and includes a very quick and fair peer-review system, which is all easy to use. Visit http://www.dovepress.com/ testimonials.php to read real quotes from published authors. 